\title{
Content with content: A content-based instruction approach to curriculum design and course assessment in academic English for business
}

\author{
Deak Kirkham
}

University of Leeds, the United Kingdom

\begin{abstract}
This article reports on the successful implementation of a content-based instruction (CBI) approach to a 6month pre-sessional academic English for business and management course at a UK university. While recognising that CBI is not a 'cure-all' and indeed that the approach brings with it particular issues, such as instructor competence in the content, the article argues CBI offers both significant and wide-ranging benefits as a language teaching approach and as such should be given greater prominence in the language teaching industry.
\end{abstract}

Keywords: language teaching, content-based instruction, academic English

\section{Introduction}

This paper reports on an ongoing and successful implementation (as judged by student feedback, peer teaching feedback and instructor introspection) of content-based instruction $(\mathrm{CBI})^{1}$ in the re-design of a 20 week pre-sessional Academic English for Business and Management (AEBM) language course at a UK university. The paper begins with an overview of relevant aspects of the CBI literature in order to contextualise the case study (section 2), after which a detailed account of the syllabus design and its motivation is given (section 3 ). Finally, (section 4), implications of the case study are drawn.

\footnotetext{
Content-based instruction is one of a number of names for a family of content-led approaches to language teaching. Others include content-based teaching (seen here as a synonym) and content and language integrated learning CLIL which Çekrezi (2011: 3822) defines as 'an approach to teaching and learning where subjects such as science, history and geography are taught and studied through the use of a non-native language'.
} 


\section{Contextualising CBI}

CBI traces its beginnings back at least three decades, to 'the mid to late 80s' (Brinton 1997 in Kasper 1997). 1986 saw the publication of both Bernard Mohan's 1986 seminal work, Language and Content, and May Shih's TESOL Quarterly article, 'content-based approaches to academic writing'. In the following year, two book-length treatments appeared (CantoniHarvey 1987 and Crandall 1987), the titles of both of which used the term 'content area'. Two years later in 1989, Brinton, Snow \& Wesche $(1989)^{2}$, who remain central contributors in the field, published Content-based second language instruction. Since these beginnings, the use of content in the language classroom has continued to inspire interest (Snow \& Brinton 1997; Valeo 2013; Wang 2013) and criticism (Bruton 2011) both in the classroom and in research. This section first considers the emergence of CBI before evaluating it as a pedagogical approach.

\subsection{Historical emergence}

CBI, in common with all language teaching methodologies, is best viewed as a family of approaches, a fuzzy category (Haack 1996) with links to and overlaps with other approaches. Attempting to define, characterise or operationalise it, then, is a task requiring sensitivity and subtlety. From a historical point of view, Eskey $(1997,132)$ cites Stern's (1981) 'brilliant, if somewhat neglected paper', which argued for a binary distinction between two types of communicative language teaching, the L-variety (for linguistics) and the P-variety (for psychology or pedagogy), the latter drawn not from an analysis of language but from an analysis of the learning process itself.

A complementary view is given by BS\&W $(1989,5-9)$, who discuss three traditions which they view as the 'roots of content-based language teaching': language across the curriculum, language for specific purposes (LSP), and immersion education. These traditions emerged out of specific pedagogical and social contexts in various Anglophone countries from the 1960s to the 1980s, and each viewed the relationship between language form and content in different ways. However, they have in common precisely that relationship: that some content, relevant to the learners, is used as a central and controlling principle of curriculum design and perhaps assessment alongside 'traditional' work on language form, which is itself integrated somehow into the content.

\subsection{Theoretical frameworks}

Despite accepting Johns' (1997) observation that no complete theoretical framework for CBI exists, this section will look at three theoretical constructs which lend support to the practice. Firstly, seminal work by Stephen Krashen (see Krashen 1981, 1982) had already established a favourable context for the use of content in language learning just prior to the emergence of the three pedagogical traditions discussed above. All of Krashen's five hypotheses can, in

\footnotetext{
${ }^{2}$ Henceforth BS\&W (1989).
} 
different ways, support a content-based approach. The acquisition-learning hypothesis argued for a natural approach (Krashen \& Terrell 1983) to language acquisition that mirrored the effortlessness of L1 acquisition and eschewed form-focused grammar teaching. The natural order hypothesis lent further support to this, taking a strong stance on the notion of a natural order of acquisition for certain language forms, including English functional suffixes (Brown 1973; Dulay and Burt 1974, 1975). These first two hypotheses led Krashen to argue for a monitor hypothesis, the monitor being a cognitive operation which applied consciously learned (in Krashen's technical sense) knowledge to the naturally acquired output. This was done best when the learner was relaxed in Krashen's view (the affective filter hypothesis). Finally, this natural process of acquisition is achieved through appropriately levelled input, $i+1$.

Much if not all of Krashen's work has been questioned; much if not all has been reworked or rejected by others. In the $21^{\text {st }}$ century's proliferation of models and theories, Krashen's early attempt at a unified theory of second language acquisition can appear somewhat simplistic. Nevertheless, his ideas received considerable attention in the 1980s, at the time CBI emerged, providing a theoretical justification for it. The notion of interesting content which is read at the learner's own pace fits snugly into Krashen's definition of input. The reframing of formal language training as sitting alongside and emanating out of the content dovetails smoothly with the connotations of the acquisition-learning hypothesis.

Perhaps foremost among those insights of Krashen that have received further attention, both from Krashen himself and others, is that of the role of extensive reading. In both L1 and L2 contexts, extensive reading has been demonstrated to improve reading ability, vocabulary and general knowledge (West, Stanovich \& Mitchell 1993; Elley 1991). This should come as no surprise: reading is a form of input, and input is a necessary condition for learning. In language learning, as opposed to, say learning to bake a cake, input in the form of reading is widely available and can be tailored to students' interests and needs. Of course, this approach comes with certain caveats, not least that the input should be of the right level, and of interest to the reader. Training may also be needed in vocabulary recording and output tasks which make the use of the input. This, of course, is what a CBI taught course would provide; the emphasis on reading itself, however, is a theoretically secure notion.

Krashen is not the authority he once was. However, the notions of extensive reading and input just beyond the level of the learner have found parallels in other theoretical approaches. For example, contemporary work by Lantolf and associates (see Aljaafreh \& Lantolf 1994; Lantolf 1994; Lantolf \& Appel 1994; Lantolf \& Pavlenko 1995) draws links between CBI and the Zone of Proximal Development (ZPD), a notion proposed but not fully worked out by Lev Vygotsky (1978). Wallace (2015) interprets the notion as follows:

... [when] students, young and old, are given tasks to accomplish that are just beyond their actual competence, but are able to secure the support of others, it is likely that they will be able to manage the task better than if they are left alone to struggle with it.

Wallace $(2015,105)$

The ZPD is an attempt to formalise the intuition that the right help, in the right way, at the right time is better than no help at all. If the reading matter stands as proxy for a human agent who guides the learner into the next proximal zone, the ZPD is a clear echo of Krashen's $i+1$. 
As a final theoretical construct, scholars such as Fathman \& Kessler (1993), Slavin (1995) and Stahl (1994) discuss the notion of private speech, i.e. the use of internal monologue for problem-solving and rehearsing, negotiation of meaning. Again this can arise in the context of private extensive reading (as opposed to the more pressured, public environment of seminar discussions or presentations) as a mechanism for driving learners through zones of proximal development, again supported if necessary by peer learning or teacher guidance.

To conclude this section, whatever weaknesses Krashen's legacy may now be seen to contain, the value of private extensive reading of the right type sits easily with other relevant pedagogical constructs. With his concern for input-led teaching, with an emphasis on meaning in context and a clear de-emphasis on (forced) production, Krashen can be seen as the first prophet of CBI.

\subsection{CBI and CLIL}

A brief detour is now made to discuss one particular variety of $\mathrm{CBI}$ in addition to the three forms of CBI discussed by BS\&W. This additional instantiation of content-based language teaching has emerged in the European context in the last 20 years. Christened CLIL - content and language integrated learning - in 1994 by its founders, David Marsh and Anne Maljers, it now boasts EU backing, for example in the form of the e-clil initiate (http://e-clil.uws.ac.uk/) and its own journal, the International CLIL Research Journal. It has been adopted by the Cambridge English Teacher Knowledge Test (Cambridge English Online) as one of their specialist modules, and has found favour with the British Council among other educational providers (British Council 2014).

CLIL is often framed within the context of European secondary school education, where the primary focus is content. By contrast, CBI can be seen as an EFL-based language school modality where the primary focus is language. However, the integration of language and content is clear in both approaches. British Council documentation (British Council, op. cit.) make clear that CLIL 'must involve the learning of the language associated with the content' and that through it 'learners are equipped with the language for thinking about the content' (italics in original). Concepts such as scaffolding, negotiation of meaning and the coconstruction of knowledge are key in this document.

Despite its acceptance by various, prestigious educational provides, CLIL has not gone unchallenged. Bruton (2011), for example, is sceptical about some of the positive results in the Basque country. In addition to highlighting methodological concerns and the small size of samples in previous work, Bruton also suggests that ostensibly positive results from a CLIL non-CLIL comparison experiment, could be interpreted as a function of the higher motivation of the CLIL groups.

\subsection{An evaluation of $C B I$}

Having traced the origins and some of the theoretical foundations of CBI, we briefly summarise its strengths and weaknesses. 


\subsubsection{In support of CBI}

CBI offers a number benefits (linguistic, cognitive and affective and to both learners and teachers). These include the following:

(a) BS\&W p. 9 comment that CBI is particularly appropriate where learners have specific functional need in the second language'. This is the backbone of the CLIL version of CBI discussed above, but remains relevant in subject specific EFL delivery such as the case study in question in this paper.

(b) Eskey $(1997,136)$ discusses CBI's emphasis on the aboutness of language: content in this sense is not merely something to practice language with; rather language is something to explore content with. This reframes language not as goal, but as means, mirroring its use in 'the real world'. In this respect CBI situates itself close to the tradition of task-based learning (TBL) (e.g. Larsson 2001; Prabhu 1987) which frames language in a similarly radical usage-based way.

(c) Kasper (1997) discusses the heightened transferability of language skills gained in a CBI context. Drawing on earlier studies (Anderson \& Pearson 1984; Nelson \& Schmid 1989), she notes that the content schemata which is built up in CBI adds an extra resource for the reader when approaching related texts. The emphasis on form adds learning capital when approaching other texts with similar content.

(d) In terms of motivation, as an input driven approach with a clear de-emphasis on output, CBI both lowers the affective filter (in Krashenite terms) and promotes autonomy and decision-making. In regard to the latter claim, if curricula are designed in such a way that students are able to make some choices as to what is read, CBI gives scope for considered, accountable decision-making, with greater flexibility and adaptability for the student.

(e) CBI can motivate teachers in that it offers them opportunities for personal, professional and intellectual development and greater control over their delivery.

\subsubsection{Limitations}

The implementation of CBI curricula has not gone unchallenged. Lee (2014) offers a postmortem on the use of CBI in Malaysia, an initiative that lasted seven years (2003-2010). Lee contrasts this situation with the ongoing use of immersion CBI in Canada, drawing attention to certain features of Malaysian society which she argues mitigated against the CBI agenda. For example, quoting Swain \& Lapkin (2005), Lee notes that Malaysia's multilingual situation meant that the various learner L1s were 'supposed to be "invisible and inaudible"', a situation contrasting considerably with Canada where students' French L1 was not relegated to a position of non-use in the educational model. Lee's other not dissimilar points concern the lack of bilingual or multilingual teachers and the differences between classroom culture and the local L1 community. Lee's criticisms of the application of CBI in Malaysia will not be challenged here. However, it must be noted that the learning context in an Anglophone country overcomes her concerns: students from a range of L1s render teacher bilingualism less relevant. 
Other limitations are now briefly listed:

(a) CBI stresses the written mode of language reception and production, downplaying the oral. Similarly, from a learning modalities point of view, there is an imbalance towards visual learners and away from auditory and kinaesthetic learners.

(b) The role of pronunciation (and indeed sound level receptive listening skills) may be underplayed.

(c) The findings of work on the importance of grammatical accuracy (for example the Focus on Form and Focus on FormS approaches (e.g. DeKeyser 1998; Long 1991) sit uneasily with CBI, where the focus on meaning in context, message and content itself frame formal accuracy as incidental.

(d) Assessment becomes more complex as the content must also be assessed.

(e) At the institutional level, current methods of teacher training assume a linguistic focus with language systems and skills at the centre. Teachers may exhibit resistance towards and reluctance to engage with CBI approaches.

\section{A case study}

Having discussed some of the dimension of CBI, we turn now to the case study which forms the centre of this paper. Section 3.1 describes the course 'as was', viewing it as a discrete skills and systems course influenced by the structure of IELTS and the administrative requirements of destination departments. Section 3.2 describes the initial changes towards a CBI-driven course with Section 3.3. discussing ongoing changes in the spirit of CBI. Section 3.4 covers exceptions to the CBI principle before 3.5 looks at future changes.

The initial motivation for what is reported in this article was to modify and indeed improve the delivery of an EAP pre-sessional syllabus. The research question, therefore, was formulated as:

(1) To what extent does a CBI-driven syllabus result in improved delivery of a business-focused EAP presessional, as reflected in student satisfaction and tutor perception?

The conclusions drawn are based on two sets of end-of-term feedback from all students on the course, comments made throughout the course and the author's own (admittedly subjective) impressions of development.

\subsection{The past}

Not unlike CBI itself, the course in question has existed under various names and in various forms for many years. Its purpose has nevertheless remained relatively constant: it is a presessional language and business course designed to prepare international students for postgraduate study in business and management. The current author began teaching on the course in April 2010 and has taught on it, latterly co-directing it, since then for either three or four out of four terms per year. 
Until approximately 2011, the course could be appropriately described as a 'skills and systems' design in the sense that reading and writing skills were taught separately, the latter in tandem with a single project. Speaking skills were also a separate strand, assessed through a presentation, listening skills as was grammar and business vocabulary (for which a standard business English coursebook was used). This structure allowed an assessment approach which mirrored the IELTS exam in that students received a mark for speaking, listening, reading and writing as separate components, with grammar and vocabulary as a fifth component.

The primary rationale for this format was the needs of receiving departments in the wider University. Because of their familiarity with the IELTS format, which reports language proficiency in a discrete four skills format (listening, reading, writing, speaking), it was considered appropriate to adhere to this format, and allow it to inform the structure of the course. In short, the motivation was as much institutional as pedagogical. While recognising the motivation for this format, collegial discussion as to the future direction of the course found itself echoing the sentiments of Garner \& Borg $(2005,119)$ that 'skills-based teaching has numerous problems and many programs are now turning to $\mathrm{CBI}$ as a means for preparing students for university study in a new language and context'.

\subsection{Initial changes}

\subsubsection{Setting off}

The course has been evolving towards its current state since approximately 2011. Staffing changes along with a growing emphasis on 'academic English' through such organisations as BALEAP, including a wider awareness of its characteristics, led to a series of informal discussions on the structure of the curriculum. Initially, a need was perceived for greater 'academic content' (or, alternatively, academic orientation) in the course and to that end, a greater reliance on primary literature was required. This raised the immediate question of 'what content?'. Two separate influences initially played a role in this selection: a) the themed units of the business vocabulary and grammar textbook which discussed broad topics such as marketing or globalisation; and b) the availability of specialist staff from the University Business School.

In terms of a), then, the first step was to 'flesh out' the vocabulary and grammar textbook with primary literature which in turn gave rise to small scale writing tasks or presentations. For example, the marketing unit was supplemented by, among others, a text on marketing blunders (Dalgic \& Heijblom 1996). Texts such as this treat a particular aspect of the broad topic of marketing in greater depth, follow the conventions of an academic article more clearly, and contain language (collocations, technical vocabulary, grammar structures) which are relevant to future academic study. In this case, the early parts of the article were read in class with an emphasis on noticing, vocabulary recording and text awareness. Students were then askedto write a short summary of the text.

In terms of $b$ ), academic colleagues from the University business school (to which the vast majority of students were heading) were asked to deliver a lecture on a particular topic and to 
suggest some pre-reading that might be covered in class. One example is a unit of work on counterfeiting which used two articles suggested by the academic colleague in addition to this individual's lecture.

At this point, the course could not yet be described as content-based. It was conceptualised as a language- and skills-driven course with certain mini-projects that had a higher degree of specialist content and as such something of a half-way house. Student feedback indicates that these innovations were clearly successful: students commented on the presence of a specialist lecturer noting in many cases a positive attitude to the focus which this brought; staff then felt empowered to add to the material brought by that lecturer. The decision was therefore taken to increase the influence of this content and as such in late 2012, the course first began to gather together themed units for a CBI delivery from January 2012. Time was given by the institution to initiate this and two staff, one of whom was the author, worked on developing content-driven units of work.

\subsubsection{Steps taken}

The following summarises the steps taken in the subsequent transformation of the course, a process conducted largely by the author in consultation with the co-director. The vast majority of these decisions were 'judgement calls' of a largely intuitive nature, based on a broad-brush understanding of the CBI literature applied to the specific context of the course. The process itself (to be detailed in the next section) seemed very natural and intuitive, something which the author now sees as a defining characteristic of CBI materials production.

Step 1:

Selection of theme descriptions on the basis of a) the language / grammar coursebook themes; b) availability of specialist staff from the Business School; c) felt levels of confidence and competence by teaching staff.

Comment: The process confirms the insights of CBI writers that the competency of staff is a key factor in determining what is taught and from what sources. As the above indicates, practicalities impinged on the decision of what to teach.

Step 2:

Collection of relevant texts; reading to learn; initial formulation of learner outcomes and assessment questions.

Comment: As BS\&W (1989) state, the selection of texts is critical. The principles detailed below emerged. However, none of these principles is unbreakable and each must be weighed against the other. Moreover, the balance of factors changes as learners develop (see also 4.3 below).

(i) It was decided that a range of business texts should be used: academic articles, companyproduced reports, and interviews or presentations from reputable sources such as TED. Range implies variety and allows exposure to different genres. 
(ii) Texts should be realistic (manageable) in length: texts must not be too daunting for preprogram students; a lengthy text of 20 or more pages is simply too much to allow meaningful engagement. In Krashenite terms, mere length raises the affective filter. Length is thus framed as a continuum, with longer texts being introduced later. However, selected sections of a lengthier text can be used thus allowing learners exposure to longer texts in principle.

(iii) Texts must have clear sections. This aids the development of support materials and renders the text less threatening in that certain 'whole' sections can be discarded. Pedagogically, this is an effective way (into/of) teaching the practice of selectivity in reading.

(iv) Texts should be readable and recent. Texts older than 10 years were in general avoided, although 'seminal' texts of more than decade's age were occasionally included.

(v) Texts should be relevant to each other and relate to each other conceptually so as to create a coherent conceptual terrain and (therefore) allow the writing of an assessment question. This conceptual relationship can be achieved in various ways: texts can build upon each other, echoing each other's central concepts; alternatively texts can present clearly different points of view, creating a 'pros and cons' conceptual structure; finally, texts can relate in a highly implicit manner to each other. All three of these combinations and variations upon them have been tried, and each has been observed to challenge students in different ways. Discussion of the nature of the relationship has proven to be an engaging classroom activity.

(vi) Texts should be academically appropriate: what counts as a source has been found to be a major element of development for pre-sessional students. Often Google scholar is initially seen as a sufficient search tool and students are reluctant or do not see the point of using the University (online) library to acquire peer-reviewed work. The sustained exposure to a range of academic and academic-related texts has appeared to be a highly inductive way of challenging these assumptions.

(vii) Varied use has been made of the following types of text: academic articles from peerreviewed papers; company documentation in the form of reports and marketing material; 'prestigious' business journalism, primarily from The Economist; and other relevant business media. Adherence to this principle facilitates exposure to a wide range of different genres of text and style, which in turn invites certain text- and languagerelated activities on the relationship between text and language form.

(viii) In later units, learners are given freedom to select some texts for themselves. This principle of 'core texts first; own texts later' fulfils the learner autonomy potential of CBI in a structured fashion. Nevertheless, guidance was still required for the majority of students.

Step 3:

Scheduling, sectioning, skills, systems and assessment

Comment: This was the most difficult stage both procedurally and conceptually. Having selected a set of texts, not only must they be ordered, and materials produced to support 
learners through the texts, but assessment tasks must be created which reference the content. After some experimentation with different formats and exercises, it was decided that a pack of support materials covering a broad range of textual and response tasks should be produced. The sections of the text were used to guide materials, and within this principle, at the risk of oversimplifying, two broad types of support materials were created:

(a) Certain key sections of texts such as abstracts or introductions were subjected to intensive exploitation for structure, language and meaning. Typically, learners might be asked first to match section headings to a multi-paragraph text, secondly, to identify key phrases in the text, thirdly, to respond to comprehension questions on the section, and fourthly, to either discuss or write a short summary. Through these means, elected key sections were felt to be relatively comprehensively covered. It was also made clear to learners that the range of tasks also acted as a self-study 'menu' for their own reading. It is a question for further research within CBI as to what extent the provision of such a 'text-attack activity menu' leads to more effective independent study.

(b) In direct contrast to the above, the materials for some sections were simply light-touch, broad-brush prompts aimed at encouraging independent note-taking. Prototypical sections for this approach were thematically connected within the text, e.g. lists of advantages and / or disadvantages. This mode of materials support was therefore often used for sections 'after' guiding or heading parts of the text which would be supported with a)-type materials, above.

At a practical level, one of the lead tutors on the course, the current author, produced the vast majority of the materials, while the other periodically acted as 'devil's advocate'. This division of labour was found to be highly productive.

\subsection{Ongoing changes}

The previous section covered changes that have taken place to date, which have shifted the course in question from a discrete skills and systems structure to a CBI course. We now consider two ongoing changes before noting elements that remained unchanged from the previous format, as well as future changes.

\subsubsection{Addressing the written production accuracy and grammar syllabus deficits}

A common criticism of CBI-style programmes is a lack of focus on grammar, specifically grammatical accuracy. This assumes, of course, that the systematic classroom-based teaching of grammar is a worthwhile enterprise, a viewpoint that has been challenged (Thornbury 2005; Truscott 1996). Valeo (2013) argues for the positive effect of a FFI / FoFs supplement to a CBI course. She notes $(2013,26)$ that grammar teaching in CBI has been noted to be ad hoc and unsystematic. In an attempt to address this, in developing the course, the 'classic' CBI approaches to systematic grammar teaching were considered. These included the following: 
- As an application of Schmidt's (1990) noticing hypothesis, relevant academic English structures in the texts (e.g. relative clauses, noun-noun compounds) were identified and their use in the text analysed. However, this was done on a text-driven basis, with reference to the language in context and rarely (although see below) were individual constructions taken out of context and practised.

- When time allowed, certain of these were practised using traditional teaching techniques. For example, with relative clauses, learners might be asked to produce a paragraph including two or more relative clauses. The paragraphs, of course, might be on a topic or theme not dissimilar to the content. For weaker students, an example paragraph in one of the texts might be used as a springboard and the learner asked to complete a paragraph in a slightly different way.

It was felt that these approaches were at least partially successful in addressing a possible (Focus on Form(S)) grammar deficit. In addition to using these approaches, however, it was made clear that the CBI approach taken was not a grammar approach and that copious grammar books were available in the language study area. Feedback, both throughout and at the end of the course, largely confirmed this with a number of positive comments on the grammar-lite approach.

\subsubsection{Online journals}

In 2013, a decision was taken to include online journals on the course with students being asked to contribute one entry per week. During the academic year 2013-2014, these were framed as open content journals: students could write whatever they wanted. Uptake was fair but variable: stronger or more motivated students approached this task enthusiastically, often writing more than one entry per week, and in some cases, very long ones; others were (or did you mean 'less') reluctant.

To address this, a number of changes were implemented for the academic year 2014-15. Firstly, tutors were more confident about the delivery and therefore this component of the course may have been 'sold' to the students more effectively. Secondly, a report style was required and two examples were given to students at the beginning of the course. This set the text-type of the journal entry and arguably gave the students greater confidence in approaching the task as a result of having a model. Thirdly, the content was more tightly defined. In line with Corbett (2003), the journal entries were framed as reports on cultural engagement. Students were given a list of possible cultural exploration activities and required to write about these.

\subsubsection{Ongoing adaptation of the texts}

As has been suggested, in the early stages of the re-writing of this course, a certain degree of control was imposed on the conceptual domains. This was partly for the benefit of tutors, including the current author, in order to allow a smooth delivery of the content-based modules. After the first year's delivery, however, tutors felt considerably more comfortable 
with the content and had grasped some of the central themes of the units. Moreover, tutors had had time to research other possible articles. As such, although the titles of the units remained the same, in many cases, texts were substituted and materials were re-written. The current author found this ongoing process highly motivating as the content of the course was slightly different (and better) in the second year.

\subsection{Elements left (partially) unchanged}

Despite the radical re-write of the course in question that this paper discusses, tutors on the course felt from the beginning that some elements of an intensive delivery should be independent of the topics and themes covered in the CBI input. To this end, the presentations component (of two hours per week) was 'left alone' as a skills course with a strongly personalised focus. Historically, this component has consisted of skills and language work taking a relatively traditional format. The availability of familiar resources also mitigated against a radical overhaul. It is generally felt that this decision has worked well. Encouragingly, however, on one or two occasions, it was still felt useful to capitalise on the content introduced through the wider course.

\subsection{Future changes}

At the time of writing, two very different changes are being discussed. One concerns the length of the theme-based units. Currently set at two weeks of real time (equal to 12 hours of input and a variable number of additional hours of self study), the issue of extending this time to three weeks has been discussed. The additional time offers the following potential benefit:

(a) More time to dig deeper into the themes and core concepts. Both a larger domain of content can be covered and, perhaps more importantly, there is time for revision of earlier content. By contrast, in the two-week delivery, it was felt that there was a 'rush' to get 'through' enough content to merit an assessment task.

(b) More time for drafting and redrafting of the written assessment tasks. This is a key element of any writing syllabus, even more so in a CBI context, where the content for a weaker student may need revisiting and for a stronger student can be developed and extended.

(c) More time for 'mini-writing tasks' which enable contextualised and content-relevant language practice. Rejecting a hard version of Krashen's input hypothesis, thisapproach to content-language integration is the one currently favoured by course deliverers who seen it as the best response to Valeo's (2013) concerns about the ad hoc nature of the teaching of formal systems. 


\section{Implications for second language learning practice and theory}

Having presented the case study in detail, we now draw some lessons for second language classroom learning.

\subsection{The institutional autonomy of pre-sessional courses}

The reader will recall that the precursor to the current course was given institutional shape by the perceived requirements of adherence to an IELTS format for reporting student scores to receiving departments. The application of CBI here can be seen as a institutionally political move in that the course was reframed around a language learning pedagogy not around the institutional requirements of receiving departments. This, of course, renders the reporting of scores an administratively and communicatively more complex task, but also serves to position Language Centres as autonomous entities within the wider University.

\subsection{The teaching of lexico-grammar}

CBI reframes language teaching in a counter-intuitive way by making the content, not the language per se a joint (if not the ostensibly main) focus of delivery, curriculum design and assessment. By de-emphasising language as a system and treating it for what it is in the real world, a mode of communication, there is a loss of 'control' over the grammatical aspects of the curriculum. This raises the profound question of how grammar can be taught and assessed in a CBI framework. As discussed in 3.3.1, this issue has not yet been resolved in the course in question and remains an ongoing focus for action research and reflection. This section presents a brief overview of the place of grammar teaching in a CBI course.

Traditional approaches to teaching grammar include grammar translation and grammar based exercises, with the grammar subsystems (alongside lexico-grammatical constructions such as collocations or idioms) presented through texts. The communicative language teaching syllabus has taken a similar view of grammar with 'units' of discrete grammar input. Classic approaches to CBI continued to conceive of grammar teaching as an explicit accompaniment to the content. In this case study, few attempts were made to introduce traditional, systematised grammar units alongside the texts. Instead, 'grammar' as discrete subsystems was largely rejected and constructions-in-context accessed through a noticing approach was adopted.

\subsection{The 4Ts: topic, theme, text and task}

\subsubsection{Exploiting texts}

Skills and systems syllabuses tend to view texts in isolation from each other. A text is chosen and a subset of language work tasks and / or reading (and possibly writing) activities are undertaken based upon it. In the case of language analysis tasks, the content of the piece may 
be irrelevant. In the case of reading and writing tasks, the text must stand more central. However, the surface or superficial meaning of the text may be emphasised at the expense of personalisation, response and critique, eschewing the deeper processing or individual approach that 'lingering' with the texts allows. Most concerning, a glance at the standard language textbook demonstrates that skills and systems approaches 'hop' from text to text with minimal concern for content continuity. The approach argued for here shifts the central principle from language and skills to content per se. If language is primarily meaning and meaning is in part meaningfulness to the learner, then content receives a much more important role.

\subsubsection{Developing awareness of conceptual networks}

CBI is content driven: the content as a set of concepts sits at the centre. The concepts themselves are found in the interpretation of a number of sources, texts or aural material. As such, there are a number of possible configurations which the concepts embodied in the texts can take. For example, if the topic is renewable energy, the first text might list a number of advantages to a range of types of renewable energy. The second text by contrast might list and discuss a number of disadvantages. This is one, fairly simple, possible conceptual structure. With these two texts, a short unit of work can easily be conceived. However, this configuration is fairly simplistic and does not mirror the more complex and implicit configurations that a postgraduate student is likely to face. Other configurations include multiple case studies around a central principle or opposing interpretations of a theory.

Naturally, content itself will determine the nature of the conceptual links; indeed, an important lesson drawn from the current case study is that perceiving the 'conceptual heart' of a particular domain of study is among the most challenging tasks of the CBI curriculum writer. Given this, and the time constraints (using the two week model suggested here), it is possible that most CBI courses are unlikely to be able to match the conceptual complexity of post-graduate study; however, as a pre-sessional course, the learning benefit of working with multiple texts which relate to each other in conceptually complex ways is clear and was mentioned in some student feedback as a positive.

\subsection{Teacher competency}

Teacher attitudes and knowledge are often cited as a potential barrier to the implementation of CBI (Cammarata 2009). This is unfortunate as the opposite is true: CBI is an opportunity for teacher development. Resistance to the method is not uncommon and confusion about it is rife. However, the fact that locating suitably qualified teachers, or at least, teachers with an understanding of the demands of a CBI-driven course, poses problems for course leaders and institutions may reflect on the initial teacher training programmes and continuing professional development, not on teachers themselves. Many common initial teacher training programs focus narrowly on some of the classic 'Cs' of language teaching: coursebooks, classrooms, coloured card and not the wider 7Cs (Kirkham 2015) including content. This 
institutional shift is not an easy one to make. The case study here, however, has advanced the claim that such a transition can be made with the right combination of confidence and curiosity, teamwork and time and that this transition can be the source of professional and personal growth.

\subsection{Assessment}

Not unrelated to teacher competency is the question of assessment. Skills and systems approaches lend themselves more easily to objective assessment through gap-fills and comprehension-based reading texts. This case study made exclusive use of essay style written response tasks. The author's experience from this case study was that creating workable assessment tasks from the content is a time consuming and complex process. It is best approached by the materials designer writing a possible essay themselves, a strategy which has the added benefits of: a) constituting a self-checking process for the materials writer as to their understanding of the content; and b) highlighting for the materials writer any content- or text-specific issues the learners may have, which in turn motivates the creation of materials which may address any such specific learning gaps.

\subsection{Not running before you can walk}

A final observation concerns the manner in which the syllabus was created. The transition began from a place of considerable familiarity with the students and the course. The course was small (c. 15 students) and was led by two individuals with a strong working relationship. The author therefore concurs with the advice and caveats in the teaching training literature (see Kaufman 1997; Peterson 1997) that the creation of a CBI course will not simply happen and that certain critical pre-conditions need to be in place. As has been suggested above, the process is inevitably time-consuming and intellectually demanding but by that very token results in the emergence of a set of relatively specialist CBI materials and curriculum design skills for the individual(s) who undertake it. As such, for an institution which wishes to move to a CBI delivery, it may be of value to consider identifying one or two individuals to take forward the process as opposed to any such shifts being a 'whole-staff initiative. Finally, on the practical side of things, the experience of the current author was that materials design and the teaching of those materials could not be separated; the entire enterprise was inherently dialectical in nature.

\section{Conclusion: content with content?}

This article has argued that the CBI revolution of the mid-to late 1980s represents a genuine innovation in adult second language learning, which frames language learning in a sociocognitive usage-based framework. Evidence was marshalled from a range of theoretical perspectives to underpin this. An extensive case study was then presented which argued for the effectiveness of the approach in the context in question, a discipline-specific pre-sessional 
academic English language course. Student feedback was very largely positive, teaching staff were highly motivated: the course worked.

Does this mean that the language teaching profession should be content with contentbased instruction? Broadly, yes. But, entirely? Probably not. The case study has suggested that the very creation of a CBI course is a demanding task, as is its delivery, and experience has shown that not all stakeholders in the industry; learners, teachers, management, are ready for it. Furthermore, it is not a cure-all and cannot always trump the real need for some kind of instruction on form per se, accuracy and other concerns. In section or example 3.4 it was argued that a largely CBI course should have elements which are separate from the content. The systems and skills aspects of delivery were of course not abandoned: noticing and practising structures and paragraph development remains at the centre, albeit led and framed by a content. CBI, is, then, very much a language teaching pedagogy: it is not content lecturing, but teaching language through content. However, done well in the right context, it leaves both teachers and students feeling content. With content.

\section{References}

Aljaafreh, A., and J. P. Lantolf. 1994. Negative feedback as regulation and second language learning in the zone of proximal development. The Modern Language Journal 78(4): 465-483.

Anderson, R.C., and P. D. Pearson. 1984. A schema-theoretic view of basic processes in reading comprehension. In P.D. Pearson (ed.), Handbook of reading research, 255-291. New York: Longman.

Brinton, D., M. Snow, and M. Wesche. 1989. Content-based second language instruction. New York: Newbury House.

British Council. 2014. CLIL policy and practice: competence-based education for employability, mobility and growth. In British Council Regional Policy Dialogues 2013-14, 65-115. https://www.britishcouncil.org/sites/ default/files/bc_regionalpolicydialogues_baja.pdf

Bruton, A. 2011. Is CLIL so beneficial or just selective? Re-evaluating some of the research. System 39: 523-532.

Brown, R. 1973. A first language: The early stages. Cambridge, MA: Harvad University Press.

Cammarata, L. 2009. Negotiating curricula transitions: Foreign language teachers learning experience with content-based instruction. The Canadian Modern Language Review 65(4): 559-585.

Cantoni-Harvey, G. 1987. Content-area language instruction: Approaches and strategies. Reading, MA: AddisonWesley.

Çekrezi, R. 2011. CLIL and teacher training. Procedia Social and Behavioural Sciences 15: 3821-3825.

Corbett, J. 2003. An intercultural approach to English language teaching. Clevedon: Multilingual Matters.

Crandall, J. (ed.) 1987. ESL through content area instruction: Mathematics, science, social studies. Englewood Cliffs, NJ: Prentics Hall Regents.

Dalgic, T., and R. Heijblom. 1996. International marketing blunders revisited: Some lessons for managers. Journal of International Marketing 4(1): 81-91.

DeKeyser, R. 1998. Beyond focus on form: Cognitive perspectives on learning and practising second language grammar. In C. Doughty, and J. Williams (eds.), Focus on form in classroom second language acquisition, 114-138. Cambridge: Cambridge University Press.

Dulay, H., and M. Burt. 1974. Errors and strategies in child second language acquisition. TESOL Quarterly 8: 129-136.

Dulay, H., and M. Burt. 1975. Creative construction in second language learning and teaching. In M. Burt, and H. Dulay (eds.), On TESOL '75: New directions in second language learning, teaching and bilingual education, 21-32. Washington, DC: TESOL.

Elley, W. B. 1991. Acquiring literacy in a second language: The effect of book-based programs. Langauge Learning 41(3): 375-411. 
Eskey, D. 1997. Syllabus design in content-based instruction. In M. Snow, and D. Brinton (eds.), The Contentbased classroom. Perspectives on integrating language and content, 132-141. New York: Longman.

Fathman, A., and C. Kessler. 1993. Cooperative language learning in school contexts. Annual Review of Applied Linguistics 13. Issues in second language teaching and learning 13: 127-140.

Garner, M., and E. Borg. 2005. An ecological perspective on content-based instruction. Journal of English for Academic Purposes 4: 119-134.

Haack, S. 1996. Deviant logic, fuzzy logic: beyond the formalism. Chicago: University of Chicago Press.

Johns, A. M. 1997. English for specific purposes and content-based instruction: What is the relationship? In M. A. Snow, and D. M Brinton (eds), The Content-based classroom: Perspectives on integrating language and content, 363-366. White Plains, NY: Addison Wesley Longman.

Kasper, L. 1997. Theory and practice in content-based EFL reading instruction. English for Specific Purposes 14(3): 223-230.

Kasper, L. 2000. Content-based college ESL instruction. Mahwah, NJ: Lawrence Erlbaum Associates.

Kaufman, D. 1997. Collaborative approaches in preparing teachers for content-based and language enhanced settings. In M. Snow, and D. Brinton (eds.), The Content-based classroom: Perspectives on integrating language and content, 175-186. New York: Longman.

Kirkham, D. 2015. Sailing the 7Cs: a grammar-lite approach to adult second language learning. IATEFL Voices, 244.

Krashen, S. 1981. Second language acquisition and second language learning. Oxford: Pergamon.

Krashen, S. 1982. Principles and practice in second language acquisition. Oxford: Pergamon.

Krashen, S., and T. Terrell 1983. The natural approach: Language acquisition in the classroom. Oxford: Pergamon.

Lantolf, J. P. (ed.) 1994. Sociocultural theory and second language learning. Special issue of The Modern Language Journal 78(4).

Lantolf, J. P., and G. Appel (eds.) 1994. Vygotskian approaches to second language acquisition, Norwood NJ: Ablex.

Lantolf, J. P., and A. Pavlenko 1995. Sociocultural theory and second language acquisition. Annual Review of Applied Linguistics 15: 108-124.

Larsson, J. 2001. Problem-based language learning: a possible approach to language education? Polonia Institute, Jagiellonian University.

Lee, S. 2014. A post-mortem on the Malaysian content-based instruction initiative. Journal of Asian Pacific Communication 24(1): 41-59.

Long, M. 1991. Focus on form: A design feature in language teaching methodology. In K. de Bot, R. Ginsberg, and C. Kramsch (eds.), Foreign language research in cross-cultural perspective, 39-53. Amsterdam: John Benjamins.

Marsh, D., and G. Lange 2000. Using languages to learn and learning to use languages. Jyväskyla: University of Jyväskyla.

Mohan, B. 1986 Language and content. Reading, MA: Addison-Wesley.

Nelson, G., and T. Schmid 1989. ESL reading: Schema theory and standardized tests. TESOL Quarterly 23: 539543.

Peterson, P. W. 1997. Knowledge, skills, and attitudes in teacher preparation for content-based instruction. In M. Snow, and D. Brinton (eds.), The Content-based Classroom: Perspectives on integrating language and content, 158-174. New York: Longman.

Prabhu, N. S. 1987. Second Language Pedagogy. Oxford: Oxford Univerisy Press.

Schmidt, R. 1990. The role of consciousness in second language learning. Applied Linguistics 11: 129-158.

Shih, M. 1986. Content-based approaches to teaching academic writing. TESOL Quarterly 20: 617-648.

Slavin, R. E. 1995. Cooperative learning ( $2^{\text {nd }}$ ed). Boston: Allyn and Bacon.

Snow, M. A., and D. M. Brinton (eds.) 1997. The content-based classroom: Perspectives on integrating language and content. New York: Longman.

Stahl, R. J. (ed.) 1994. Cooperative learning in social studies: A handbook for teachers. Reading, MA: AddisonWesley. 
Stern, H. H. 1981. Communicative language teaching and learning: toward a synthesis. In J. E. Alatis, H. B. Altman, and P. M. Alatis (eds.) The second language classroom, 133-148. New York: Oxford Univeristy Press.

Swain, M., and S. Lapkin. 2005. The evolving sociopolitical context of immersion education in Canada: Some implications for program development. International Journal of Applied Linguistics 15: 169-186.

Thornbury, S. 2005. Dogme: dancing in the dark? Folio 9(2): 3-5.

Truscott, J. 1996. The case against grammar correction in L2 writing classes. Language Learning 46: 327-369.

Valeo, A. 2013. The integration of language and content: Form-focussed instruction in a content-based program. Canadian Journal of Applied Linguistics, 16(1): 25-50.

Vygotsky, L. 1978. Mind in Society. The development of higher psychological processes. Cambridge, MA: Harvard University Press.

Wallace, S. 2015. A dictionary of education ( $2^{\text {nd }}$ ed.). Oxford: Oxford Univeristy Press.

Wang, Y. 2013. A literature review on content ESL instruction. Journal of Language Teaching and Research 4(3): 642-647.

West, R. F., K. E. Stanovitch, and H. R. Mitchell. 1993. Reading in the real world and its correlates. Reading Research Quarterly 28: 34-50. 